\title{
Corporate Social Responsibility in Supply Chains of Small and Medium-
}

\section{Sized Enterprises}

\author{
Hee-Yong Lee \\ Yeungnam University \\ 280 Daehak-Ro, Gyeongsan, Gyeongbuk \\ South Korea, 712-749 \\ E-mail: ilugit@ynu.ac.kr \\ Dong-Wook Kwak \\ Coventry University \\ Priory Street, Coventry \\ United Kingdom, CV1 5FB \\ E-mail: d.kwak@coventry.ac.uk \\ Jeong-Yang Park (corresponding author) \\ The University of Nottingham \\ Wollaton Road, Nottingham \\ United Kingdom, NG8 1BB \\ E-mail: jeongyang.park@nottingham.ac.uk
}

This is a pre-print (non-publisher's document). Please cite this article as below:

Lee, H-Y., Kwak, D-W., and Park, J-Y. (2017) Corporate social responsibility in supply chains of small and medium-sized enterprises, Corporate Social Responsibility and Environmental Management. (accepted and forthcoming) 


\title{
Corporate Social Responsibility in Supply Chains of Small and Medium- Sized Enterprises
}

\begin{abstract}
Research has shown that implementation of corporate social responsibility (CSR) practice represents a considerable challenge for small and medium-sized enterprises (SMEs). This research conceptualises the dimensions and contingencies of CSR in SMEs' supply chains. Drawing on institutional theory and stakeholder theory, we investigates the degree of importance and implementation of CSR practices in SMEs. A large-scale questionnaire survey with SMEs in manufacturing sectors and panel discussions were conducted in South Korea. The findings indicate that SMEs tend to focus on explicit CSR practices that can be easily identified by their customers. Consistent with this, stakeholder and institutional pressures were valid in the performance of CSR practices, but largely biased to customers, government and regulatory pressures. Based on institutional theory and stakeholder theory as overarching theoretical lenses, this research contributes to offer a fuller understanding of dimensions of CSR practices in the supply chains from a SME perspective.
\end{abstract}

Keywords: corporate social responsibility, institutional theory, small and medium-sized enterprises, South Korea, stakeholder theory, supply chain management 


\section{Corporate Social Responsibility in Supply Chains of Small and Medium- Sized Enterprises}

\section{Introduction}

In line with the increasingly shared consensus that organizations should implement corporate social responsibility (CSR) practices, the form and concept of CSR has become prevalent in business research which led to various conceptualisations by scholars. To date, developing a widely-accepted conceptualisation of CSR is highly contested in the literature (Heikkurinen and Ketola, 2012; McWilliams et al., 2006; Mohr et al., 2001; Welford et al., 2007). Given the complexity of the CSR concept, it is viewed mainly from four perspectives: as a social obligation, as a stakeholder obligation, as an ethics-driven process and as a strategic managerial process (Maignan and Ferrell, 2004; Oberseder et al., 2013). Within these CSR perspectives, CSR research and practice lies on a paradox between a notion of voluntary basis or behaviour of social concerns in companies' operations (Vilanova et al., 2008) and an opposing notion of social responsibilities that is typically mandated by law (Campbell et al., 2012). In any cases, the awareness of corporate social responsibility by the public has been increasing, which led firms to implementing CSR practices across their supply chains.

The integration of CSR into supply chains has drawn much attention both from practitioners and researchers with the current emphases on the triple bottom line of economic, environmental and social concerns of business operations. However, sustainable supply chain management (SSCM) research is largely biased to economic and environmental aspects (Hall and Matos, 2010), which highlights the importance of CSR research focusing on both environmental and social impacts of the business beyond economic concerns. Research on 
CSR practices in supply chain management (SCM) is rather limited but it is becoming a field of increasing interest, with research particularly concentrating on the CSR practices and activities of large companies in their supply chains. Within CSR in SCM research, the implementation of environmental and social standards along the supply chains (e.g. Seuring and Muller, 2008) and the risks and challenges related to implementing and complying with these environmental and social standards (e.g. Lim and Philips, 2008) have been studied. Implementing CSR practices into the supply chain can be challenging and yet, despite the increasing awareness of implementing CSR into supply chains, many firms, specifically small and medium-sized enterprises (SMEs), struggle to see the real value of CSR practices in terms of competitive advantages across the supply chains (Welford and Frost, 2006).

Due to the fact that the distribution of CSR complements the supply chains by linking buyers and suppliers, the focus should integrate responsibilities of and for those parties into a company's role to implement the socially responsible businesses. In addition, the scope is limited to large companies and public authorities, neglecting SMEs in the sustainability debates (Achabou et al., 2015; Johnson, 2015). With CSR becoming increasingly critical to the today's organizations whether small or large, there is need to fully understand the CSR debates of SMEs as they tend to struggle to implement CSR practices. Indeed, SMEs are in a weak position in supply chains and possess less resources, scope of operations and visibility compared to large firms, which often leads to SMEs' passive reactions to CSR practices and implementations. Given the research gaps, this research aims to conceptualise the dimensions of CSR in supply chains and investigate the degree of implementation of these CSR practices from an SME perspective. It also explores the drivers of CSR which initiate and motivate firms to adopt CSR based on the institutional theory (Kim et al., 2013) and the stakeholder theory (Park and Ghauri, 2015) as overarching theoretical lenses. 
We believe that having a multidisciplinary perspective contribute to advancement of research on CSR in supply chains. Under this notion, we provide a consolidated dimensions to investigate CSR and SCM relationships and advance the theoretical understanding of CSR in SME's supply chains. The objectives of this paper are three-fold. The first is to conceptualise the dimensions of CSR in supply chains, highlighting which CSR dimensions are prioritised in the practice. The second is to demonstrate to what degree SMEs implement CSR practices. The third is to explore the drivers of SMEs' CSR practices based on institutional theory and stakeholder theory. We employ the empirical findings of SMEs' supply chains to illustrate this theoretical development. In order to address the objectives, we investigated South Korean SMEs in the manufacturing industries who are involved in global supply chains. We conducted a large scale questionnaires with manufacturing SMEs in Gyeongbuk province in South Korea.

The remainder of this paper is structured as follows. In the next section, we review the extant research that shed light on the dimensions and drivers of CSR in supply chains. Then, the methodological approach of the empirical study is explained and then the findings are presented and discussed. Finally, conclusions are drawn including theoretical and practical implications for SME management with limitations of the study.

\section{Literature Review}

\section{CSR in SMEs' Supply Chains}

For the purpose of this paper, we take the view of CSR as a concept whereby companies go beyond and extend to the grounding CSR on a voluntary basis and integrate the greater notion of socially binding responsibilities in their business operation and in their interface with their stakeholders. Thus, our study adheres to the definition by McWilliams and Siegel (2001, p. 
117) where they define CSR as 'actions that appear to further some social good, beyond the interests of the firm and that which is required by law'. This interpretation of CSR suggests the potential dimensions of CSR practices of business operations where CSR is firmly connected to institutions of stakeholder or government involvement (Brunton et al., 2015; Heikkurinen and Ketola, 2012). Engaging with stakeholders, CSR can be viewed as an imperative organisational task for firms in order to address ethical, social, environmental and economic demands (Park and Ghauri, 2015).

Extending the notion of CSR to not only being socially responsible within the organisation internally, CSR encompasses the idea of being responsible socially and environmentally throughout its supply chain (Pedersen and Andersen, 2006). Research on how to integrate CSR in SCM is rather limited but it is becoming a field of increasing interest, with research particularly concentrating on the CSR practices and activities of large corporations in their supply chains. Within CSR in supply chains, the implementation of environmental and social standards along the supply chains (e.g. Seuring and Muller, 2008) and the risks and challenges related to implementing and complying with these environmental and social standards (e.g. Lim and Philips, 2008) have been researched.

Implementing CSR practices into the supply chains can be challenging and yet, despite the increasing awareness of implementing CSR into supply chains, many firms struggle to see the real value of CSR practices in terms of business profits and performance. In particular, traditional concepts of CSR cannot fully capture the social responsibilities of supply chains beyond a company. Due to the fact that the distribution of CSR complements the supply chains by linking buyers and suppliers, it is highly required to take buyers and suppliers into account for implementing sustainability with supply chains. For this reason, Carbone et al. (2008) distinguished supply chain-level responsibilities from business-level responsibilities 
while incorporating both social and environmental dimensions for both levels. However, there are just a few studies which consider the uniqueness of supply chain level responsibilities, thus conceptualisation of these aspects is not common in the literature.

With respect to the organisational size in CSR-related activities and practices, the literature tends to focus commonly on large corporations such as multinational enterprises (MNEs) in developed countries (Jackson et al., 2008) and neglects SMEs in the current sustainability and sustainable development debates (Bos-Brouwers, 2010; Cassells and Lewis, 2011; Lee et al., 2016.). There is a clear knowledge gap in the link between CSR-SMEs (Perez-Sanchez et al., 2003; Russo and Perrini, 2010) although SMEs make up over 90 percent of the global population of corporations and offer more than half of employment in both developed and developing economies (Jamali et al., 2009; Udayasankar, 2008). Consequently, SMEs produce major contributions in social and economic related activities (Udayasankar, 2008). Given their importance, this gap needs to be addressed by focusing on CSR putting emphasis specifically on SMEs. Towards a more holistic approach in CSR, there is a need for more research into CSR in SCM specifically from a SME perspective (Ayuso et al., 2013; Pedersen, 2009). Typically, SMEs often seem to possess intrinsic differences when compared with large corporations. These differences come in the form of legal structures, policies, sector, strategic orientation toward profit and institutional forms (Perrini, 2006).

Within SMEs environment, extant CSR theories and instruments suited for MNEs may not be applicable for SMEs (Bos-Brouwers, 2010). In particular, SMEs typically possess passive reactions towards CSR and sustainability partly due to insufficient financial resources and competencies as well as informal management systems compared with large corporations which put them in the weak position implementing CSR-related organisational practice (Park and Ghauri, 2015; Jenkins, 2004; McWilliams and Siegel, 2001). Typically informal nature of 
SMEs' management system is often seen as a hindering factor to adopt and implement CSR practices (Baumann-Pauly et al., 2013). For SMEs, the commitment to CSR tends to be implicitly reflected in their internal structures and procedures with no formalised system to promote CSR practices and processes (Baumann-Pauly et al., 2013). In this vein, BaumannPauly et al. (2013) indicate that large organisations seem to be better equipped at organising and implementing CSR explicitly in their formal organisational practices and procedures which allow them to interact efficiently with stakeholders when compared to SMEs. In both cases for SMEs and large organisations, the collaboration with external society plays a key driver in promoting and implementing the CSR practice (Baumann-Pauly et al., 2013; ReyesRodriguez et al., 2016; Winsor, 2006). Knowledge about these enabling and inhibiting aspects could provide the CSR implementation practice in SMEs and under this premise, this research incorporates a comprehensive stakeholder and institutional based framework to understand CSR in SMEs, to which we now turn.

\section{The Dimensions of CSR from Stakeholder Theory and Institutional Theory}

In principle, both stakeholder theory and institutional theory are interlinked and contribute to CSR on various levels which provide a guide to the drivers that initiate and motivate SMEs to adopt CSR as well as the enablers that facilitate SMEs in achieving CSR activities in their business practices. Accordingly, we can suggest possible avenues to illustrate the dimensions of CSR in supply chains and demonstrate the degree of implementation of these CSR practices from SMEs' perspectives integrating stakeholder theory and institutional theory. Stakeholder theory specifies the extent to which corporations interact with their stakeholders appropriately (Laczniak and Murphy, 2006). It also illustrates the dimensionality of CSR practices or thinking which can be used as a guiding tool in the implementation and 
evaluation of CSR into business operations (Mishra and Suar, 2010).

In the conceptualisation of CSR, the centrality of stakeholders has been emphasised by Campbell (2007). The primary stakeholders can include any individual, group, organisation, institution, community and the environment (Spiller, 2000) as well as internal managers and employees, customers, investors, government and suppliers (Panapanaan et al., 2003). They can even include any groups that may be required for long-term business survival and management (Mitchell et al., 1997). Over the last twenty years, several SSCM literatures discuss wide-ranging forms of stakeholders which affect pressures to adopt sustainable thinking, practices or activities (Gonzalez-Benito and Gonzalez-Benito, 2006; Wolf, 2013).

More precisely, current research on CSR from stakeholder perspectives fails to include discussion of all or wider stakeholder mandates (Obersede et al., 2013). The omission of all or wider stakeholders is partly due to poor and different conceptualisation of CSR in the literature and practice which affects directly or indirectly the identification of accurate boundaries for whom corporations are responsible (Donaldson and Preston, 1995; Jones, 1995). The tensions between business-driven and stakeholder-driven systems and issues of CSR are closely inter-related. Within the stakeholder perspective, there are various ways in which stakeholders determine significant parts in supply chains as facilitators as well as hinderers. Thus, SMEs are required to take in all stakeholders 'who can affect, or are affected by, the achievement of an organization's mission' (Freeman, 1984, p. 54). Consequently, developing CSR for SMEs is complex and involves strategic decisions to formulate how they encounter CSR activities or sustainability goals into their operations at a corporate level (Polonsky and Jevons, 2009; Schneider and Wallenburg, 2012). More importantly, BaumannPauly and Scherer (2012) highlight the importance of interacting and engaging with relevant internal as well as external stakeholders which can facilitate SMEs to adapt their internal 
organisational structures in order to ensure the embeddedness of CSR related practices.

While the role of stakeholders has been widely researched, the role of institutions has been relatively ignored in CSR research (Brammer et al., 2012). Institutional theory determines companies are socially embedded within a set of formal institutions such as government regulation and informal institutions such as norms, conventions and shared beliefs (North, 1990). In this vein, it facilitates to identify the different boundaries between business associations and society. Within the dominant stands in institutional theory, there are two aspects of CSR: the diversity and the dynamics of CSR (Tempel and Walgenbach, 2007). Scott (1995) illustrates several social and cultural pressures that SMEs may face and be required to fulfil within their specific institutional environments and networks for social norms and rules. Given that the stakeholders' demands are linked to the institutional pressures (Reimann et al., 2012; Yang and Rivers, 2009), in complying with these institutional pressures, SMEs in supply chains may require adaptations of their values, processes, structures and business practices. In the course of institutionalisation, CSR takes a wider boundary of the market and government regulations. Thus, an institutional theory views CSR practices beyond the territory of voluntary action.

This paper critically examines the contributions of stakeholder theory and institutional theory to understanding the CSR practices in SCM and to investigating CSR-SME relationships. Underpinned by these two theoretical foundations, this research conceptualise the key dimensions of organising and implementing CSR in practices specifically from a SME perspectives.

\section{Research Methodology}

The aim of this paper was to conceptualise the dimensions of CSR in supply chains and to 
explore their relative importance and implementation from SMEs' perspectives. Also, it sought to investigate the drivers of CSR implementation based on institution theory and stakeholder theory. The empirical data for this study are from a large-scale questionnaire survey with South Korean SMEs in manufacturing sectors and panel discussions, to which we turn next.

\section{Survey Data Collection}

To investigate the CSR in supply chains, a large-scale questionnaire survey was conducted with SMEs in South Korea. The survey sample was constrained to the manufacturing firms which directly or indirectly involved in global supply chains so that supply chain contexts can be fully integrated into the survey responses. South Korea is a rapidly developing economy which has recently increased awareness of the CSR issues in its global SCM. For this research, Gyeongbuk province in South Korea was selected for its long tradition of strong focus on manufacturing sectors. A total of 200 questionnaires were distributed via email to SMEs based in the province from February to March 2015. The list of these SMEs for this survey was obtained from a government organisation, Gyeongbuk Pride Product Support Centre which supports the internationalisation and marketing of SMEs in the region since 2009. South Korean government defines a SME as a firm which employ fewer than 300 employees in the manufacturing sector.

The questionnaire consists of four parts. Following the first part which asked general information about participating firms and respondents, the second part was designed to measure the relative priority of CSR dimensions and CSR practices by pair-wise comparisons. In the third part, respondents were asked to assess the implementation level of CSR practices 
in their organisations. The last part covered the evaluation of contingencies that may affect the level of CSR implementation based on institutional theory and stakeholder theory, namely regulatory impact, normative impact, cognitive impact (institutional theory) and customers, government, suppliers, competitors, local community and non-governmental organisations (NGOs) (stakeholder theory). The third and fourth parts were measured by 7-point scales. Before commencing the large-scale survey, this questionnaire was reviewed by CSR experts and then by a pilot study to examine the applicability and validity of measurement items.

$$
\text { < Insert Table } 1 \text { here >> }
$$

A total of 87 questionnaires were collected from top and middle managers, showing the response rate of $43.5 \%$ which is a relatively moderate response rate compared to that of other SCM research. In CSR research, this response rate may be lower than some previous surveys (i.e. Sangle 2010; Strachan 1999), but still higher than other surveys (i.e. Beske et al., 2008; Holt 2004). We acknowledge the limited sample size of this research. No missing data and non-response biases were detected, thus all responses were used for the analysis. The profile of respondents is shown in Table 1.

\section{Data Analysis}

\section{Research Procedure}

For this paper, step-wise analysis using analytic hierarchy process, importance-performance matrix and ANOVA were used. In the following sections, we outline six step-wise processes of the research procedure in detail. 


\section{Step 1 - Define CSR dimensions in supply chains}

Step 1 generates a vital theoretical framework to comprehensively understand the dimensions of CSR applicable both to corporate level and supply chain levels. In particular, it focused on the social responsibility of supply chains and its operational definitions. A thorough review of extant CSR-SCM literature was conducted to construct the framework of multi-faceted CSR dimensions which are holistic yet parsimonious. This framework reviewed by a panel discussion of five industry experts in CSR and modified according to their feedbacks to ensure their validity. Based on the framework, a survey questionnaire was designed to capture (1) pairwise comparisons between CSR dimensions, (2) the implementation level of each dimension and (3) the impacts of institutional factors and stakeholders on CSR.

\section{Step 2 - Evaluate the relative importance of CSR dimensions}

Step 2 aims to understand which dimension is perceived the most important in SMEs' CSR in the supply chain context. In particular, the importance of a supply chain social responsibility dimension can be numerically evaluated in comparison of established CSR dimensions. Analytic hierarchy process (AHP) is a technique for multiple criteria decision making (Saaty, 1977) which can produce the relative importance of each criterion by pairwise comparisons between criteria. The application of AHP in this research can provide specific priorities among CSR dimensions. In the large-scale questionnaire survey, the respondents are asked the pairwise comparisons between three main CSR dimensions (corporate environment dimension, corporate social dimension and ethical supply chain dimension) and between subdimensions of each CSR dimension. On the 9-point scale to each end, the respondents evaluate the extent to which they think one dimension is more important than the other. The results will be converted into $1 / 9$ to 9 scales as suggested by Saaty (1980), and individual 
responses will be summarised as a representative perception using geometric means.

\section{Step 3 - Demonstrate the average implementation level of CSR dimensions}

At Step 3, the implementation level of CSR dimensions will be captured by the mean of 7point-scale measurement from the large-scale questionnaire survey.

\section{Step 4-Analyse the importance and performance by a $2 X 2$ matrix}

With the results from Step 2 (relative importance) and Step 3 (performance), a performanceimportance matrix can be generated with mean-centred values. 'Relative' importance will be used for this matrix which is the main difference from the normal performance-importance matrix. Further discussion is made from this matrix to evaluate the CSR practice of SMEs in supply chains.

\section{Step 5 - Generate three groups by Overall Weighted Index}

With AHP results being used as a weight of each dimension of CSR in supply chains, the

Overall Weight Index (OWI) of CSR implementation of respondent firms can be derived (Jharkharia and Shankar, 2007). The OWI can be calculated by the following formulae:

$$
\begin{gathered}
\mathrm{OWI}=\sum_{i}(\text { Weight }) i \times(\text { Performance }) i \\
(i=\text { a sub-dimension of } \mathrm{CSR})
\end{gathered}
$$

Based on the OWI, respondents can be grouped into upper, medium and lower groups in terms of CSR implementation.

Step 6 - Validate the impacts of various drivers on CSR practices 
The impacts of various drivers on CSR practices from institutional theory and stakeholder theory can be validated by comparing the perception of these drivers between the upper and lower groups. If the drivers are effective, the mean values of the upper group should be significantly higher than those of the lower group. If there exists a statistically significant mean difference in driver A, its impact on CSR implementation can be confirmed. Analysis of Variance (ANOVA), a statistical tool to test as to whether the mean of two or more groups is equal or not, will be used and the statistical significance will be tested with the $5 \%$ significance level.

\section{Results}

Following step-wise research process, the results are presented in five sections: dimensions of CSR in supply chains; relative importance of CSR dimensions; the level of CSR implementation; performance-importance matrix of CSR dimensions; and the impacts of CSR drivers.

\section{(1) Dimensions of CSR in Supply Chains}

In general, CSR consists of the environmental dimension and the social dimension. But most CSR literature dedicates its focus to the social dimension, dividing it into several subdimensions, such as labour, health and safety, human rights, community, society and etc. The environmental dimension, on the contrary, tend to be captured by just one dimension although green logistics and/or SSCM literature described this dimension with details, including but not limited to material handling, waste management and packaging and transport (Rodrigue et al., 2009; Zhu et al., 2008.). Moreover, since the current CSR dimensions are developed from an individual firm's perspective, it is challenging to capture 
the CSR dimension applicable to the supply chain level. Therefore, it is pre-requisite to find appropriate CSR dimensions in supply chains.

$$
<\text { Insert Table } 2 \text { here }>>
$$

For this purpose, the review of existing literature on CSR, green logistics and SCM was conducted. In particular, Global Reporting Initiative (GRI) (2013)'s Sustainability Reporting Guidelines (GRI-G4) was useful because they suggested comprehensive criteria to be applied to a firm's CSR. At the supply chain level, only a few SCM research focused on how to implement CSR across the supply chain, and suggested supplier assessment, ethical collaboration (Gimenez and Tachizawa 2012), awareness building and training (Ciliberti et al., 2008) and evolution of governance (Alvarez et al., 2010). In particular, Carbone et al. (2008) explicitly distinguished CSR from supply chain social responsibility by considering measurement items for both environmental and social aspects of supply chains.

One critical difference of this research is the creation of an 'ethical supply chain' dimension to address CSR issues in supply chains. The extant studies on CSR focused social and environmental dimensions, which are in line with GRI-G4 applicable to the report of 'a company'. However, when supply chains with various entities are considered, it is necessary to have another viewpoint which can incorporate the social responsibilities from suppliers to end customers. In this circumstance, this research has used the same practices and indicators discussed by literature and GRI-G4, but aligned them with corporate environment, cooperate social as well as ethical supply chain dimensions.

A set of CSR dimensions and their practices were identified based on GRI-G4 and extant research, and then reviewed by five CSR experts. They discussed CSR dimensions and 
practices for a parsimonious model, which led to a debate as to whether the supply chain dimension should take the same hierarchy as the environmental and social dimensions. Some of them suggested four dimensions taking the model of Carbone et al. (2008) consisting of corporate-social, corporate-environmental, SC-social and SC-environmental dimensions into account. Eventually they agreed that at least one supply chain dimension should be needed to capture the unique contributions of sustainable supply chain management to CSR. As a result, the framework of CSR dimensions in supply chains can be drawn as can be seen in Table 2 .

\section{(2) Relative importance of CSR dimensions}

Based on the CSR consolidated dimensions, the relative importance of each dimensions and their practices were calculated by AHP. Four analysis were conducted using SuperDecisions software package to identify the relative weights among three CSR dimensions and among practices within a dimension. All the analyses showed the consistency indices less than the threshold value of 0.1 , which means the responses were logically consistent. The results are demonstrated in Table 3 in a descending order of relative weights. Two established dimensions, Corporate Society and Corporate Environment, accounted for $80 \%$ of the importance with similar levels of weights between the two. The Ethical Supply Chain dimension, on the other hand, was perceived less important than the other two. However, it also accounted for $20 \%$ of the total importance, showing the potential to be an independent dimension that can effectively illustrate CSR in supply chains.

$$
<\text { Insert Table } 3 \text { here }>>
$$

At the practice level, health \& safety was highly prioritised by SMEs (20.64\% out of 
$100 \%$ ). This will be attributed to the fact that SMEs have less number of employees who are exposed to dangerous working conditions. Other two social practices, local community and labour, have drawn attentions of SMEs to significant extents (11.72\% and $11.48 \%)$. Two environmental practices, environment products (15.00\%) and environmental sites (11.72\%), were ranked highly whilst material management was perceived relatively low. Three practices in the ethical supply chain dimension placed at the bottom, which is mainly because the dimension itself was less important than other two established dimensions. The relative weights of CSR practices will be further discussed in Step 4 along with their performance levels.

\section{(3) The level of CSR implementation}

The level of CSR implementation was measured by the mean. The results show that consumer protection (5.3 out of 7 ) is the most implemented practice, which is followed by environmental products (5.01) and environmental sites (4.86). While local community (4.6), supplier assessment (4.6), health \& safety (4.53) and ethical collaboration (4.52) are located in the middle of the table, labour (4.47) and material management (4.37) were selected as the least implemented practices. This finding is in line with empirical findings of Achabou et al. (2015) and Carbone et al. (2012), which showed the implementation of customer-related as well as environment-related practices was higher than that of society-related practices.

\section{(4) Performance-Importance Matrix of CSR dimensions}

To analyse the implementation level in combination with the relative importance of each CSR sub-dimension, a $2 \mathrm{X} 2$ matrix was generated as shown in Figure 1. All values were modified to be mean-centred. Among the CSR practices, environmental products and sites were well 
recognised by SMEs, and at the same time, were embedded in their CSR practices well. Consumer protection, on the other hand, was heavily implemented in the practice, but its importance was relatively low. These practices are, in common, explicit to customers, which can easily build up relatively good social reputation.

Figure 1 illustrates the importance of practices in the corporate social dimension which was highly regarded but the implementation level was less than expected. In particular, health and safety was not appropriately addressed by SMEs despite its highest importance. This can be explained by cost issues because these practices will require immediate spending which cannot be easily implemented by SMEs given their financial constraints. If SMEs seek their competitiveness from cost advantages, emphasis on practices for the society can be just rhetoric. On the contrary, two major environmental practices including environmental products and environmental sites, were rated highly both in terms of importance and performance. This results reflect the fact that environmental aspects have been regarded as established drivers of a firm's competitive advantage by SMEs.

\section{$<$ Insert Figure 1 here $>>$}

In terms of the operational aspects, they are often implicit to customers which were not highly considered by SMEs. These include supplier assessment, ethical collaboration and material management, which commonly require a certain level of strategic decisions to implement into the operations. In particular, these operational practices are one of the prolific research agenda in the SCM disciplines which have suggested many innovative ideas, but SMEs tend to be less focused on these practices. In addition, this can be explained by power relations in the supply chain. With less power in the supply chain, SMEs may be limited to 
prioritise and initiate supplier assessment, ethical collaboration as well as material management. With regards to the material management practice, SMEs have to use enough energy and best materials, regardless of their environmental impacts, to meet the requirements of powerful customers.

\section{(5) The impacts of CSR drivers}

Given the relative weights of CSR practices and the performance of participating companies, the overall CSR level of each SME can be calculated. The highest and lowest CSR levels were 5.8 and 3.15 out of 7 , which indicated that there are clear discrepancies in CSR implementation across the SMEs. Also, it meant that there should be some contingencies which create this difference. This research thus further tested the impacts of contingencies from stakeholder theory and institutional theory on SMEs' CSR level by comparing the means of the better group and the worse group. From stakeholder theory, we identified six factors (customers, government, suppliers, competitors, NGOs and local community) and three factors (regulatory, normative and cognitive pressures) were drawn from institutional theory as shown in Table 4.

$<$ Insert Table 4 here $>>$

The ANOVA results showed that there are significant differences in CSR implementation level given all these contingencies. This implies that the theories are effective even in the SMEs and the supply chain contexts. When the overall mean values are considered, drivers of customers and government from stakeholder theory and regulatory pressures from institutional theory showed the highest mean values. The finding is in line with other studies 
which have explored the relationships between stakeholder/institutional pressures and CSR implementations (see Kim et al., 2013; Meixell and Luoma, 2015). Park and Ghauri (2015) have found that consumer, competitors and NGOs are the primary determinants of CSR practices of SMEs, but this study showed that all stakeholder pressures can generate significant changes in the practice. Interestingly, when the overall mean values are considered, customers and government from the stakeholder theory showed the highest mean values, which is quite consistent with Park and Ghauri (2015). When it comes to the institutional theory, regulatory pressures showed the highest mean values compared to those of normative and cognitive pressures. This finding can demonstrate that, if SMEs are under scrutiny of various stakeholders or regulations, their participation in the CSR practices will be general high (Udayasankar, 2008).

\section{Conclusions and Implications}

CSR has become a centre of attention for scholars and practitioners because of its wellrecognised importance to developing sustainable practices. This research explores the dimensions of CSR in SMEs' supply chains, and examined how SMEs considered CSR practices by analysing their importance and performance. This paper provides an essential insight specifically in the context of South Korea. Based on stakeholder theory and institutional theory, this research also investigated the impacts of various contingencies on the level of CSR implementation. Given the complexity of CSR implementation process, it can be concluded that SMEs tend to focus on explicit CSR practices that can be easily identified by their customers. On the contrary, operational issues hidden to their customers are not considered in SMEs' CSR practices. Such characteristics of SMEs being as resource constraints, imbalanced power within their relationships with customers, deficiencies in CSR 
strategies and lack of supply chain innovation may explain this trait in SMEs' CSR.

From the above discussion, ANOVA analysis empirically shows that stakeholder and institutional pressures are valid in the performance of CSR practices for SMEs. However, the level of pressures was largely biased to external pressures (Darnall et al., 2008) such as customers, government and regulatory pressures, which mean that SMEs tend to be more reactive rather than proactive to implement CSR practices. This can imply that SMEs recognise CSR issues as risk sources that generate stakeholder's reaction and in turn lead to damage to their firms (Hofmann et al., 2014). In this regard, this research has its value in investigating CSR practices within supply chains specifically taking the SME perspective, which have not been fully explored in the SCM discipline on its own merits.

Interpreting our findings of this study yields several theoretical, practical and policy implications. The study empirically analysed the practices and contingencies of CSR implementation using survey data and various statistical techniques including AHP, importance-performance matrix and ANOVA, which effectively demonstrated the strong and weak areas of SMEs' CSR activities. It is applicable to other industry sectors for comparative analysis but individual environments will differ significantly. The impacts of contributing factors from institutional theory and stakeholder theory have been validated even in the SMEs' contexts. These theoretical values can be also applicable to managerial implications. The CSR dimensions and practices can be used as a check list for firms to achieve balanced CSR implementation. In addition, to evaluate the degree of CSR implementation our theoretical framework can be used as an index to compare the CSR level of the SMEs.

In highlighting the dimensions of CSR in the SME context, this study holds implications for public policy. SMEs make up over $90 \%$ of the global population of corporation whether in developing economies or developing economies which therefore have 
significant contributions in social and economic related activities (Jamali et al., 2009; Naeem and Welford, 2009. Udayasankar, 2008). Given their importance, governments should develop specific policies on CSR for SMEs as typically SMEs have intrinsic differences when compared with large organisation which come in the form of legal structure, policies, strategic orientation toward profit and institutional forms (Perrini, 2006).

Due to the fact that typically SMEs display passive reactions towards CSR because of their financial constraint and limited systems which often place SMEs in the weak position implementing CSR practices, governments should raise CSR awareness and practices through soft policies on SME and offer consultation more widely. Government organisations could also introduce incentive system or partial financial assistant to SMEs in supporting the CSR practices (McWilliams and Siegel, 2001). In this way SMEs' commitment to CSR could be better reflected in their internal structures and procedures explicitly which allow them to also engage with stakeholders (Baumann-Pauly et al., 2013). The collaboration with external society including stakeholder engagement plays an important dimension in motivating and implementing CSR practices (Winsor, 2006).

Despite the fact that our research is based on CSR in SMEs' supply chains, we believe that our discussions and findings are instructive for considering the development of larger organisational CSR capabilities taken as a whole. Therefore, this paper is of high relevance to practitioners and policy makers looking to implement and manage CSR practices for organisations. Overall, this paper offers a useful insight by highlighting consolidated dimensions in CSR supply chains in manufacturing SMEs in South Korea which could provide a basis for companies developing CSR practices in developing economies. 


\section{Limitations and Future Research}

As with all research, this research has several limitations which offers indications of the potential avenues for future research. In conducting the survey with SMEs in a single developing country context in the manufacturing sectors with a focus on SMEs, it limits the degree of likely generalizability of the findings of this research. Further research could explore a comparative analysis with larger firms in other environmental contexts such as service industries which may highlight the distinctive features of SMEs' CSR practices in supply chains for replications. In this paper, we collected a total of 87 out of 200 questionnaires and the relatively low response rate (43.5\%) might be due to the fact that CSR might be a sensitive issue for some of manufacturing SMEs in South Korea. The relatively small sample size of firms limits the generalizability. Another limitation is related to the selfperception issues when conceptualising the CSR dimensions as well as interpretations of our findings which requires some caution when interpreting our empirical results.

Further, other limitations include the single response, cross-sectional nature of this research which may not offer an overall picture of the dimensions of CSR implementation process over time. Further research can employ longitudinal approach to offer fuller understanding of CSR implementation in order to extend or conform our results. Building on these limitations, further research could replicate the research methodology to other developing countries and industries and it could be complemented with qualitative research which may strengthen our findings. This study, however, provides insights into understanding SMEs' CSR at a fundamental level. 


\section{Acknowledgement}

The authors would like to thank the editor and two anonymous reviewers of this journal for their constructive suggestions and guidance.

\section{References}

Achabou MA, Dekhili S, Hamdoun M. 2015. Environmental upgrading of developing country firms in global value chains. Business Strategy and the Environment 26: 224238.

Alvarez IG, Lorenzo JMP, Dominguez LR, Sanchez IMG. 2010. Are social and environmental practices a marketing tool? Empirical evidence for the biggest European companies. Management Decision 48(10): 1440-1455.

Ayuso S, Roca M, Colome R. 2013. SMEs as "transmitters" of CSR requirements in the supply chain. Supply Chain Management: An International Journal 18(5): 497-508.

Baumann-Pauly D, Scherer AG. 2012. The organisational implementation of corporate citizenship: An assessment tool and its application at UN Global Compact participants. Journal of Business Ethics 117(1): 1-17.

Baumann-Pauly D, Wickert C, Spence LJ, Scherer AG. 2013. Organizing corporate social responsibility in small and large firms: Size matters. Journal of Business Ethics 115: 693-705.

Beske P. Koplin J, Seuring S. 2008. The use of environmental and social standards by German first-tier suppliers of the Volkswagen AG. Corporate Social Responsibility and Environmental Management 15(2): 63-75.

Bos-Brouwers HEJ. 2010. Corporate sustainability and innovation in SMEs: Evidence of themes and activities in practice. Business Strategy and the Environment 19: 417-435.

Brunton M, Eweje G, Taskin N. 2015. Communicating corporate social responsibility to internal stakeholders: Walking the walk or just talking the talk. Business Strategy and the Environment 26(1): 31-48.

Campbell JL. 2007. Why would corporations behave in socially responsible ways? An 
institutional theory of corporate social responsibility. Academy of Management Review 32(3): 946-967.

Campbell JT, Eden L, Miller, SR. 2012. Multinationals and corporate social Responsibility in host countries: Does distance matter. Journal of International Business Studies 43(1): 84-106.

Carbone V, Moatti V, Vinzi VE. 2012. Mapping corporate responsibility and sustainable supply chains: an exploratory perspective. Business Strategy and the Environment 21: 475-494.

Cassells S, Lewis K. 2011. SMEs and environmental responsibility: Do actions reflect attitudes? Corporate Social Responsibility and Environmental Management 18: 186199.

Darnall N, Jolley J, Handfield RB. 2008. Environmental management systems and green supply chain management. Business Strategy and the Environment 18: 30-45.

Donaldson T, Preston LE. 1995. The stakeholder theory of the corporation: Concepts evidence, and implications. Academy of Management Journal 20: 65-91.

Freeman RE. 1984. Strategic Management: A Stakeholder Approach, Boston: Pitman.

Gimenez C, Tachizawa EM. 2012. Extending sustainability to suppliers: a systematic literature review. Supply Chain Management: An International Journal 17(5): 531543.

Hall J, Matos S. (2010) Incorporating impoverished communities in sustainable supply chains. International Journal of Physical Distribution \& Logistics Management, 40(1/2): 124-147.

Heikkurinen P, Ketola T. 2012. Corporate responsibility and identity: from a stakeholder to an awareness approach. Business Strategy and the Environment 21: 326-337.

Hofmann H, Busse C, Bode C, Henke M. 2014. Sustainability-related supply chain risks: conceptualization and management. Business Strategy and the Environment 23: 160172.

Holt D. 2004. Managing the interface between suppliers and organizations for environmental responsibility - an exploration of current practices in the UK. Corporate Social 
Responsibility and Environmental Management 11(2): 71-84.

Jackson T, Amaeshi K, Yavuz S. 2008. Untangling African indigenous management: Multiple influences on the success of SMEs in Kenya. Journal of World Business 43(4): 400416.

Jamali D, Zanhour M, Keshishian T. 2009. Peculiar strengths and relational attributes of SMEs in the context of CSR. Journal of Business Ethics 87: 355-377.

Jenkins H. 2004. A critique of conventional CSR theory: An SME perspective. Journal of General Management 29: 55-75.

Johnson MP. 2015. Sustainability management and small and medium-sized enterprises: Managers' awareness and implementation of innovative tools. Corporate Social Responsibility and Environmental Management 22: 271-285.

Kim CH, Amaeshi K, Harris S, Suh C-J. 2013. CSR and the national institutional context: the case of South Korea. Journal of Business Research 66: 2581-2591.

Laczniak GR, Murphy PE. 2006. Normative perspectives for ethical and socially responsible marketing. Journal of Macromarketing 26: 154-177.

Lee K-H, Herold DM, Yu A-L. 2016. Small and medium enterprises and corporate social responsibility practice: A Swedish perspective. Corporate Social Responsibility and Environmental Management 23: 88-99.

Maignan I, Ferrell OC. 2004. Corporate social responsibility and marketing: an integrative framework. The Journal of the Academy of Marketing Science 32(1): 3-19.

McWilliams A, Siegel D. 2001. Corporate social responsibility: A theory of the firm perspective. Academy of Management Review 26: 117-127.

Mitchell RK, Agle BR, Wood DJ. 1997. Toward a theory of stakeholder identification and salience: defining the principle of who and what really counts. The Academy of Management 22(4): 853-886.

Naeem MA, Welford R. 2009. A comparative study of corporate social responsibility in Bangladesh and Pakistan. Corporate Social Responsibility and Environmental Management 16: 108-122.

Oberseder M, Schlegelmilch, BB, Murphy PE. 2013. CSR practices and consumer 
perceptions. Journal of Business Research 66(10): 1839-1851.

Park BI, Ghauri PN. 2015. Determinants influencing CSR practices in small and medium sized MNE subsidiaries: A stakeholder perspective. Journal of World Business 50: 192-204.

Pedersen E. 2009. The many and the few: rounding up the SMEs that manage CSR in the supply chain. Supply Chain Management 14(2): 109-116.

Perez-Sanchez D, Barton JR, Bower D. 2003. Implementing environmental management in SMEs. Corporate Social Responsibility and Environmental Management 10: 67-77.

Polonsky M, Jevons C. 2009. Global branding and strategic CSR: An overview of three types of complexity. International Marketing Review 26(3): 327-347.

Reyes-Rodriguez JF, Ulhoi JP, Madsen H. 2016. Corporate environmental sustainability in Danish SMEs: A longitudinal study of motivators, initiatives, and strategic effects. Corporate Social Responsibility and Environmental Management 23: 193-212.

Saaty TL. 1980. The Analytic Hierarchy Process, New York: McGraw Hill.

Sangle S. 2010. Critical success factors for corporate social responsibility: a public sector perspective, Corporate Social Responsibility and Environmental Management 17(4): 205-214.

Schneider L, Wallenburg CM. 2012. Implementing sustainable sourcing-does purchasing need to change? Journal of Purchasing and Supply Management 18: 243-257.

Scott RW. 1995. Institutions and organisation, Thousand Oaks, CA: Sage.

Strachan PA. 1999. Is the Eco-Management and Audit Scheme (EMAS) Regulation an effective strategic marketing tool for implementing industrial organisations? Corporate Social Responsibility and Environmental Management 6: 42-51.

Tempel A, Walgenbach P. 2007. Global standardization of organizational forms and management practices? What new institutionalism and the business-systems approach can learn from each other. Journal of Management Studies 44(1): 1-24.

Russo AF. Perrini. 2010. Investigating Stakeholder Theory and Social Capital: CSR in Large Firms and SMEs. Journal of Business Ethics 91(2): 207-221. 
Udayasankar K. 2008. Corporate social responsibility and firm size. Journal of Business Ethics 83(2): 167-175.

Vilanova M, Lozano JM. Arenas D. 2008. Exploring the nature of the relationship between CSR and competitiveness. Journal of Business Ethics 87: 57-69.

Welford R, Chan C, Man M. 2007. Priorities for corporate social responsibility: a survey of businesses and their stakeholders. Corporate Social responsibility and Environmental Management 15:52-62.

Welford R, Frost S. 2006. Corporate social responsibility in Asian supply chains. Corporate Social responsibility and Environmental Management 13: 166-176.

Winsor D, 2006. Corporate social responsibility: Three key approaches. Journal of Management Studies 43: 93-114.

Yang X, Rivers C. 2009. Antecedents of CSR Practices in MNCs' Subsidiaries: A stakeholder and institutional perspective. Journal of Business Ethics 86(2): 155-169.

Zhu Q, Sarkis J, Lai K-H, Geng Y. 2008. The role of organizational size in the adoption of green supply chain management practices in China. Corporate Social Responsibility and Environmental Management 15: 322-337. 
Tables

\begin{tabular}{|c|c|c|c|c|c|}
\hline \multicolumn{2}{|c|}{ Position } & \multicolumn{2}{|c|}{ Industry Experience } & \multicolumn{2}{|c|}{ Industry } \\
\hline CEO & $13.8 \%$ & $11-15$ years & $21.8 \%$ & Machinery & $18.4 \%$ \\
\hline Director & $50.6 \%$ & $16-20$ years & $35.6 \%$ & Apparel & $17.2 \%$ \\
\hline $\begin{array}{c}\text { Senior } \\
\text { Manager }\end{array}$ & $35.6 \%$ & Over 20 years & $42.6 \%$ & Automotive & $14.9 \%$ \\
\hline & & & & Chemical & $13.8 \%$ \\
\hline \multicolumn{2}{|c|}{ Annual Turnover } & \multicolumn{2}{|c|}{ Number of Employees } & IT Equipment & $4.6 \%$ \\
\hline US\$ 1M-10M & $3.4 \%$ & $10-50$ & $1.1 \%$ & Electronics & $4.6 \%$ \\
\hline US\$ 10M-50M & $52.9 \%$ & $51-100$ & $32.2 \%$ & Food & $2.3 \%$ \\
\hline US\$ 50M-100M & $43.7 \%$ & $100-299$ & $66.7 \%$ & Others & $24.1 \%$ \\
\hline
\end{tabular}

Table 1: The profile of survey respondents

\begin{tabular}{|c|c|c|}
\hline Dimensions / Practices & Descriptions & $\begin{array}{l}\text { GRI-G4 } \\
\text { Category }\end{array}$ \\
\hline \multicolumn{3}{|c|}{ 1. Corporate Environment Dimension } \\
\hline (1) Material Management & $\begin{array}{l}\text { Proactive management to pursue efficient use } \\
\text { of energy and materials and reduction of } \\
\text { waste in production }\end{array}$ & $\begin{array}{l}\text { EN1 } \\
\text { EN3 EN7 } \\
\text { EN23, EN30 }\end{array}$ \\
\hline (2) Environmental Sites & $\begin{array}{l}\text { Company sites with less greenhouse gas } \\
\text { emission, water withdrawal and pollution, } \\
\text { hazardous waste and spills }\end{array}$ & $\begin{array}{l}\text { EN8 EN10 } \\
\text { EN15 EN21 } \\
\text { EN22 EN26 }\end{array}$ \\
\hline $\begin{array}{l}\text { (3) Environmental } \\
\text { Products }\end{array}$ & $\begin{array}{l}\text { Products and packages which used recycled } \\
\text { materials and/or other materials with less } \\
\text { environmental impacts }\end{array}$ & $\begin{array}{l}\text { EN2 } \\
\text { EN27, EN28 }\end{array}$ \\
\hline \multicolumn{3}{|c|}{ 2. Corporate Social Dimension } \\
\hline (1) Labour & $\begin{array}{l}\text { Practices to improve diversity in labour, job } \\
\text { equality, job standard and training } \\
\text { opportunities }\end{array}$ & $\begin{array}{l}\text { LA1 LA4 } \\
\text { LA9 LA11 } \\
\text { HR1 HR9 }\end{array}$ \\
\hline (2) Health \& Safety & $\begin{array}{l}\text { Occupational health and safety initiatives to } \\
\text { reduce accidents, injury, diseases, } \\
\text { absenteeism }\end{array}$ & LA5 LA8 \\
\hline (3) Local Community & $\begin{array}{l}\text { Practices to increase a firm's contribution to } \\
\text { local community and to decrease any negative } \\
\text { impacts }\end{array}$ & $\begin{array}{l}\mathrm{SO} 1, \mathrm{SO} 2 \\
\mathrm{SO} 6\end{array}$ \\
\hline \multicolumn{3}{|c|}{ 3. Ethical Supply Chain Dimension } \\
\hline (1) Supplier Assessment & $\begin{array}{l}\text { Selection of new suppliers screened by } \\
\text { environmental and social criteria; Assessment } \\
\text { of negative environmental and social impacts } \\
\text { from suppliers }\end{array}$ & $\begin{array}{l}\text { EN32, EN33 } \\
\text { LA14, LA15 } \\
\text { SO9, SO10 }\end{array}$ \\
\hline (2) Consumer Protection & $\begin{array}{l}\text { Responsibility for products to protect } \\
\text { consumers' health and safety }\end{array}$ & PR1 PR9 \\
\hline (3) Ethical Collaboration & $\begin{array}{l}\text { Removal of any anti-competitive behaviours } \\
\text { using power imbalance and non-compliance of } \\
\text { laws }\end{array}$ & $\mathrm{SO} 7, \mathrm{SO} 8$ \\
\hline
\end{tabular}

Table 2: Dimensions of CSR in supply chains 


\begin{tabular}{|l|c|c|c|}
\hline \multicolumn{1}{|c|}{ Dimensions } & Weight & Practices & Weight \\
\hline Corporate & $36.11 \%$ & Health \& Safety & $20.64 \%$ \\
Environment & & Environmental Products & $15.00 \%$ \\
Dimension & & Environmental Sites & $13.41 \%$ \\
& & Local Community & $11.72 \%$ \\
Corporate Social & \multirow{2}{*}{$43.84 \%$} & Labour & $11.48 \%$ \\
Dimension & & Consumer Protection & $8.01 \%$ \\
& & Material Management & $7.70 \%$ \\
Ethical Supply Chain & \multirow{2}{*}{$20.05 \%$} & Supplier Assessment & $7.27 \%$ \\
Dimension & & Ethical Collaboration & $4.77 \%$ \\
\hline \multicolumn{1}{|c|}{ Total } & $\mathbf{1 0 0 \%}$ & Total & $\mathbf{1 0 0 \%}$ \\
\hline
\end{tabular}

Table 3: The weights of CSR dimensions

\begin{tabular}{|c|c|c|c|c|c|c|c|c|}
\hline \multirow{2}{*}{\multicolumn{2}{|c|}{ Drivers }} & \multirow{2}{*}{ Mean } & \multicolumn{2}{|c|}{ Upper Group } & \multicolumn{2}{|c|}{ Lower Group } & \multirow{2}{*}{ F-value } & \multirow{2}{*}{ Sig. } \\
\hline & & & Mean & S.D & Mean & S.D & & \\
\hline \multirow{6}{*}{$\begin{array}{c}\text { Stakeholder } \\
\text { Theory }\end{array}$} & Customers & 5.38 & 5.85 & 0.65 & 4.86 & 0.75 & 41.446 & 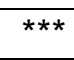 \\
\hline & Government & 4.8 & 5.34 & 0.73 & 4.36 & 0.73 & 37.987 & $* * *$ \\
\hline & Suppliers & 4.51 & 4.78 & 0.57 & 4.29 & 0.71 & 12.245 & $\star *$ \\
\hline & Competitors & 4.51 & 4.80 & 0.68 & 4.07 & 0.60 & 27.209 & $\star \star \star *$ \\
\hline & NGOs & 4.46 & 4.98 & 0.79 & 4.00 & 0.54 & 43.259 & $\star * \star$ \\
\hline & Local Community & 4.29 & 4.68 & 0.61 & 3.93 & 0.46 & 40.412 & 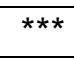 \\
\hline \multirow{3}{*}{$\begin{array}{c}\text { Institutional } \\
\text { Theory }\end{array}$} & $\begin{array}{l}\text { Regulatory } \\
\text { Pressures }\end{array}$ & 4.74 & 5.20 & 0.71 & 4.36 & 0.49 & 39.228 & $* * *$ \\
\hline & $\begin{array}{l}\text { Normative } \\
\text { Pressures }\end{array}$ & 4.39 & 4.83 & 0.77 & 4.00 & 0.54 & 32.277 & $* * *$ \\
\hline & $\begin{array}{l}\text { Cognitive } \\
\text { Pressures }\end{array}$ & 4.32 & 4.54 & 0.74 & 4.14 & 0.65 & 6.622 & * \\
\hline
\end{tabular}

Table 4: ANOVA results 
Figure

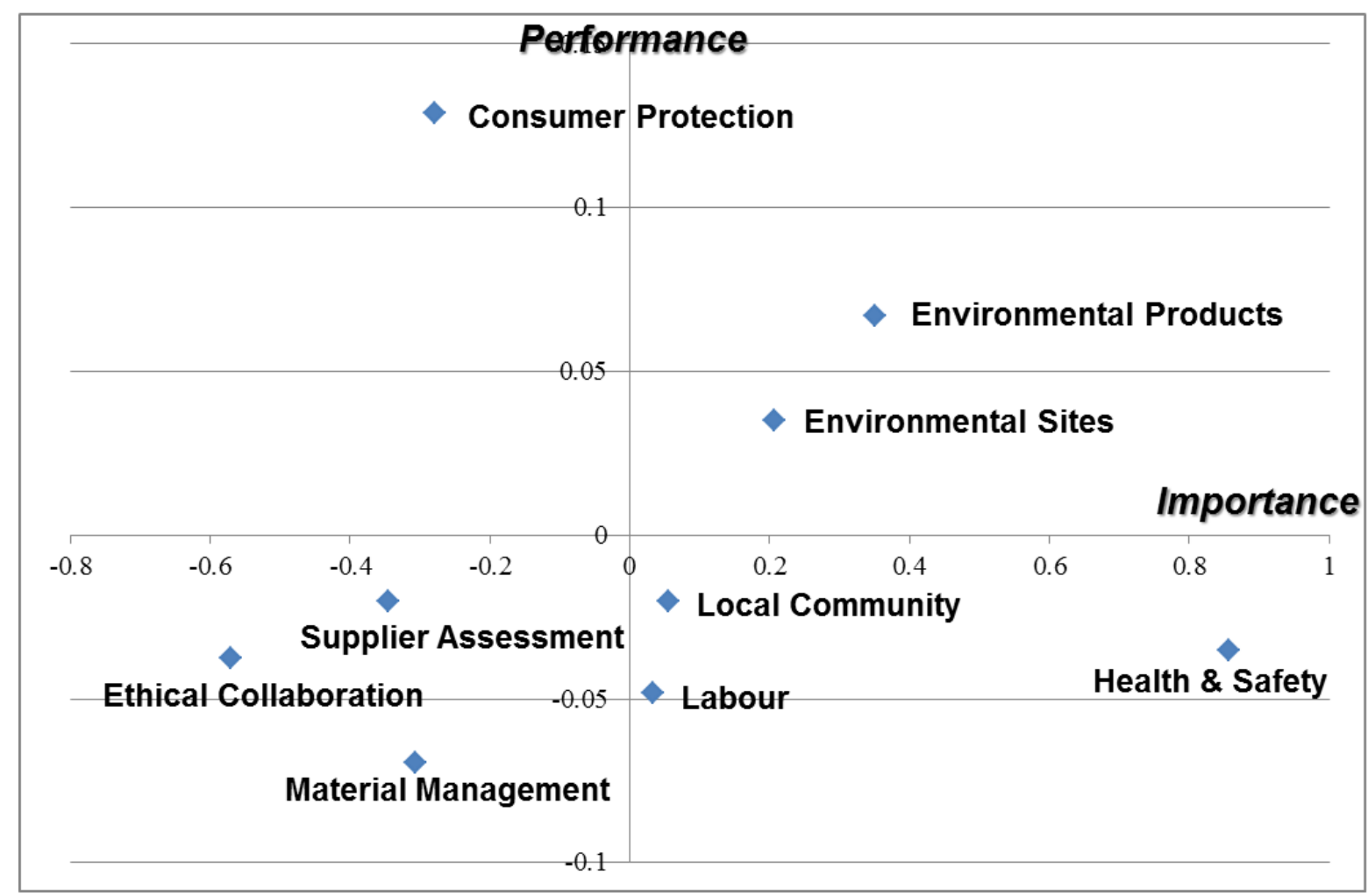

Figure 1: Performance-Importance matrix of CSR dimensions 